\title{
Dorsal epidural spinal lipomatosis
}

\author{
S Chibbaro, ${ }^{1}$ G Mirone, ${ }^{2}$ M Nouri, ${ }^{2}$ P Di Emidio, ${ }^{2}$ M Polivka, ${ }^{2}$ M Marsella, ${ }^{2}$ B George ${ }^{2}$ \\ ${ }^{1}$ Department of Neurosurgery, Hôpital Lariboisière, Paris, France; \\ 2Department of Neurosurgery, Lariboisière University Hospital, Paris, France
}

Correspondence to S Chibbaro, schibbaro@hotmail.com

\begin{abstract}
Summary
The authors report a case of a thoracic epidural spinal lipomatosis causing severe neurological deficits along the review of pertinent literature. The patient is a 56 -year-old woman who presented with acute onset of severe paraparesis; she was investigated with cervical and thoracic MRI and then surgically managed because of an intraspinal mass compressing the cord. The operation consisted in the excision of the mass confirmed to be a fibrolipoma by pathological analysis. The patient attained complete neurological recovery and at 18 months follow-up she reported a generalised well-being. Thoracic lipomas are rare lesions that presenting mostly with back pain; however, in rare instances they may cause progressive and/or abrupt neurological dysfunction. Appropriate imaging can help in the diagnosis and management of such cases.
\end{abstract}

\section{BACKGROUND}

Spinal fatty deposits have been classified into different entities depending on their location and pathological features: lipomyelomeningocele, fatty filum, intradural spinal lipoma (SL), epidural lipomatosis and spinal angiolipoma. They are all very uncommon and may cause symptoms correlated to mass effect as well as disruption of the natural cord alignment. Spinal epidural lipoma (SEL) may occur when excessive amounts of epidural fat are synthesised. The most common clinical setting for this condition to develop is in patients receiving exogenous steroid agents, although it is sporadically reported in cases of severe obesity. Even more rarely, an acute myelopathy or cauda equina syndrome resulting from epidural lipomatosis will necessitate decompressive surgery. In this paper, the authors report a very rare case of dorsal epidural spinal lipomatosis causing severe neurological deficits along the review of pertinent literature.

\section{CASE PRESENTATION}

\section{History}

A 56-year-old overweight woman (body mass index, 31 $\mathrm{kg} / \mathrm{m}^{2}$ ) was referred to our attention with a 20-day history of progressive severe paraparesis, urinary retention and upper-back pain. The time between the onset of her symptoms and the diagnosis was about 2 months. Her medical history was consistent with essential hypertension, depression and diabetes (type II) recently diagnosed.

\section{Clinical examination}

On neurological exam, the patient was unable to walk or stand up due to severe spastic paraparesis (Ashworth scale was $2 / 5)$. Deep tendon reflexes were pathologically brisk with decreased pin-prick and joint position sensation and sensory level at T6; urinary retention and reduced anal sphincter tone were also present.

\section{INVESTIGATIONS}

A contrast MRI of the thoracic spine documented a T4, T5 extramedullary mass occupying most of the spinal canal and displacing the cord laterally (figure 1A,B). The differential diagnosis of this lesion included thoracic schwannoma and meningioma.

\section{TREATMENT}

The patient underwent to emergent T3-5 hemilaminectomy. A yellowish-fatty mass which was causing marked cord compression was seen in the epidural space attached to the emergence of the T4 nerve root. The entire lesion was removed by gentle dissection from the dura and nerve root. At this stage, as the ultrasounds were not available in the operating room - the dura was opened for inspection of the intradural compartment, which resulted normal. Histopathological examination showed a fibroadipose tissue (figure 2) and the final diagnosis was of spinal extradural lipoma.

\section{OUTCOME AND FOLLOW-UP}

In the immediate postoperative period, the patient's condition improved rapidly; she was able to walk with minimal aid, by the third postoperative day.

In addition, she regained optimal bladder and bowel function. Ultimately she could be discharged home within a week. Weight-loss regimen was recommended. At the time of her most recent F/U (18 months) clinical examination was consistent with full recovery and normal neurological function. A late imaging check showed neither residual nor tumour recurrence.

\section{DISCUSSION}

SLs are rare entities. The typical location of these lesions is intradural $(60 \%)$, but they may occur intramedullary or extradurally. ${ }^{1}$ 


\section{BMJ Case Reports}
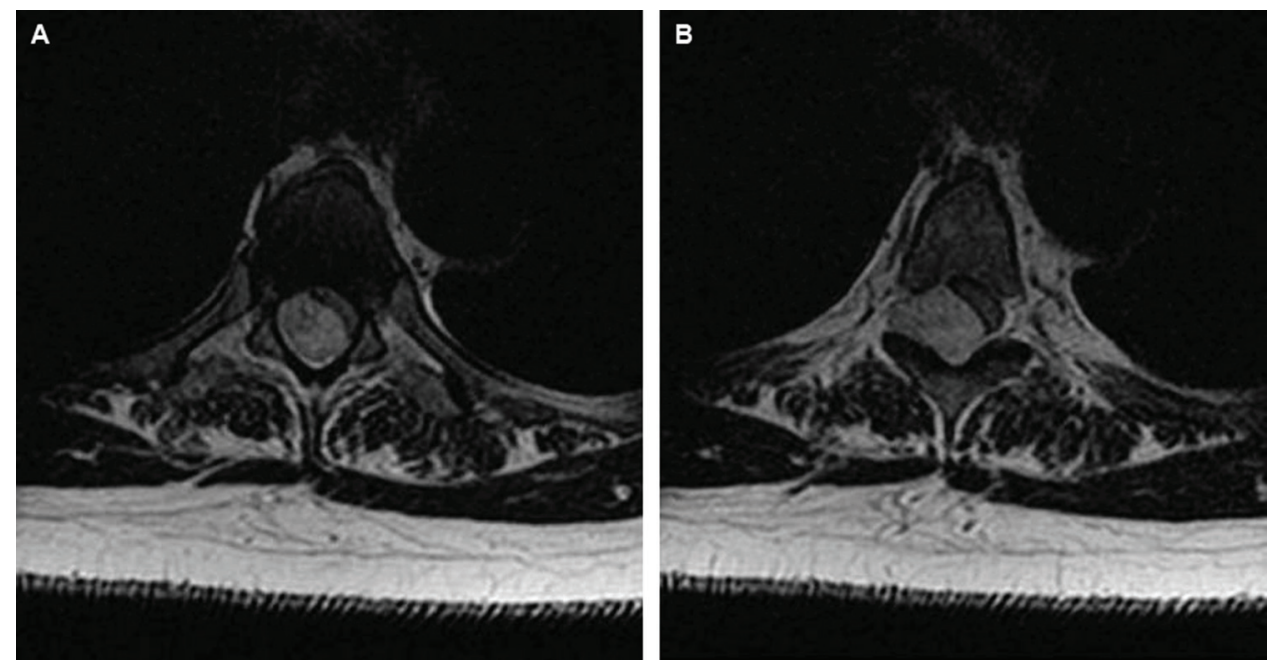

Figure 1 (A) and (B) Axial T1 enhanced MRI showing a T4 intraspinal hyperintense mass lesion displacing laterally the cord suggestive of either a meningioma or a schwannoma.

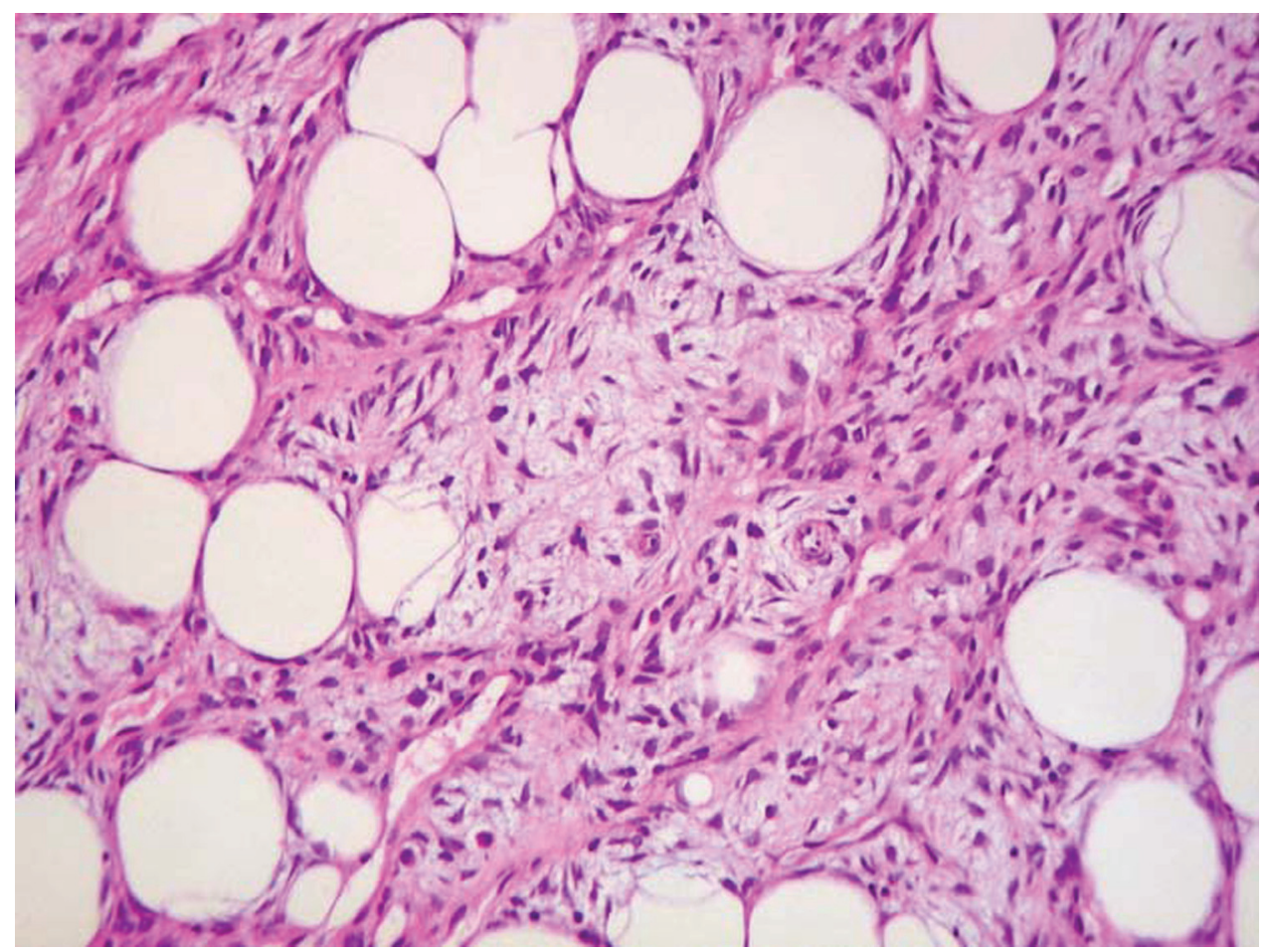

Figure 2 'Mixture of mature adipocytes and uniform spindle cells with a single elongated nucleus devoid of atypia; some collagen fibres and normal capillaries are also present (H\&E, original magnification: $\times 160)$.

These lesions have a predilection for the lumbar (39$42 \%)$ and thoracic region (58\% and $61 \%$ of cases) and may extend over several levels; isolated adult cervical location has been reported very rarely to our knowledge. ${ }^{1}$ Several authors suggested that women are more prone to develop SL in lumbar location ${ }^{2}$; however, these lesions do occur more commonly in men than women, with a ratio of $3: 1 .^{2}$ Although the mean age of patients with SL reported in literature is 43 years, the disorder tends to occur at a younger age in male patients. ${ }^{2}{ }^{3}$ The youngest patient with SL was a 6-year-old boy who was receiving high-dose steroid therapy. ${ }^{4}$ Our case report describes an overweight patient discovered to have a SEL in the thoracic spine. More than one-third of SEL cases reported in the English literature were described as idiopathic. SEL is most commonly observed in patients receiving long-term exogenous steroid therapy $(70 \%$ of cases of the series that have been reported), ${ }^{3}$ but can also be seen in patients with endogenous steroid overproduction (Cushing's disease), a number of non-steroid-related cases have been reported, including some associated with hypothyroidism, pituitary prolactinoma, obesity ${ }^{5-7}$ 
or idiopathic disease. ${ }^{3}$ In any case, the hypertrophic epidural adipose tissue causes a reduction of the spinal canal diameter compressing the neural elements with resulting progressive myelopathy and/or radicular syndrome. The natural history of SL is unknown. When a neurological deficit is present at the time of diagnosis, a slow progression of neurological symptoms is the rule ${ }^{8-10}$ although back pain is the most common complaint. The chronic pain, often lasting several months to several years, ${ }^{11}$ is generally followed by progressive or sudden neurological deficits. Lower-extremity weakness is also a common complaint and appears to be slowly progressive in most cases. Sensory changes with numbness, paresthesias or radicular symptoms are also frequent. Bowel and bladder incontinence are rare complaints. On physical examination, lower-extremity weakness is the most common finding associated to decreased pinprick sensation and altered reflexes. ${ }^{2}{ }^{5}$ Obviously, the symptoms are dependent on the level of pathology (spinal cord, conus medullaris or cauda equina), with thoracic levels causing myelopathic features and lumbar levels being associated to radicular problems. In our case, the patient had no general and longstanding metabolic problem and presented with progressive neurological deterioration that had been recognised 5 days before the diagnosis. Plain spine x-ray was normal. MRI is the investigation of choice because of its multiplanar perspective and different acquisition sequences able to pinpont the characteristic signal changes seen within fat-containing structures. Although MRI in most cases shows both the site and extent of compression, it may be occasionally difficult to interpret. The compression can be appreciated on axial and sagittal MR images, and high-signal intensity on T1-weighted images and a low signal on T2-weighted images are characteristic of adipose tissue. Epidural adipose tissue that has a thickness greater than $7 \mathrm{~mm}$ has been reported to be the diagnostic criterion for SEL (see also figure 1). ${ }^{5}$ It is also true that SL could be misdiagnosed by meningioma and/or neurinoma. The low density of the fat tissue is the pathognomonic appearance of lipoma on CT. ${ }^{1}$ It can be a useful adjunct for diagnosis, but it is not uncommon for the diagnosis to be made only at surgery. Management strategy of SL remains still controversial. Treatment options include conservative therapy and surgical intervention. Given the limited number of cases, clinical trials have not been performed to compare outcomes of conservative and surgical management. Usually patients with progressive neurological deficits are best managed with surgical decompression; their recovery can be either immediate or slow over a period of months. For patients who are considered to be at high-surgical risk, conservative treatment is indicated. ${ }^{12}$

Conservative therapy (weaning from steroids and weight loss), was successful in a number of cases. ${ }^{3} 13$ However, many patients receive steroid medications for other chronic diseases and tolerate poorly weaning from the therapy. Conservative treatment is also recommended for patients without significant cord compression and associated significant comorbidities contraindicating anaesthesia. Weight loss has been reported to be very successful in patients in whom obesity is thought to be the cause of the adipose hypertrophy. ${ }^{5}$ Patients not receiving steroids should undergo endocrinological evaluation to rule out excessive endogenous corticosteroid production. In most cases, treatment of endogenous corticosteroid overproduction should be undertaken before spinal decompression is considered. Surgical intervention, with decompressive laminectomy and resection of epidural adipose tissue, is reserved for patients in whom conservative measures fail. In general it appears that the majority of patients who were treated aggressively with surgery have improved or completely recovered from their preoperative neurological deficits. ${ }^{5}$ Improvement after surgical decompression was superior in patient with lumbar lipomatosis than those who had thoracic location, ${ }^{2}$ and when the SL was idiopathic. ${ }^{5}$ Recurrence after surgery is very rare. ${ }^{14}$ In our case, emergency surgery was undertaken due to important neurological function impairment; furthermore in the first instance, the differential diagnosis was between spine meningioma and schwannoma - schwannoma being the final diagnosis a great surprise for us. We felt surgery to be mandatory in order to give the patient every chance of recovery and we do believe that even though the hypothesis of a lipoma would have been considered, it would have not changed our management.

\section{Learning points}

- SEL is a condition most commonly associated with long-term use of steroids, but can be associated to a number of other conditions.

- Conservative treatment, with either weight loss and/or weaning from steroids, can successfully reduce epidural adipose tissue leading to clinical improvement.

- Urgent decompressive surgery with resection of epidural adipose tissue is strongly suggested for patients in whom conservative treatment fails and/or in whom neurological function is much compromised and/ or rapidly progressing.

\section{Competing interests None}

Patient consent Obtained.

\section{REFERENCES}

1. Erdocan B, Bavbek M, Altinors N, et al. Cervical intramedullary lipoma not associated with spinal dysraphism: case report. Turk Neurosurg 2002;12:46-9

2. Roy-Camille R, Mazel C, Husson JL, et al. Symptomatic spinal epidural lipomatosis induced by a long-term steroid treatment. Review of the literature and report of two additional cases. Spine 1991;16:1365-71.

3. Stern JD, Quint DJ, Sweasey TA, et al. Spinal epidural lipomatosis: two new idiopathic cases and a review of the literature. J Spinal Disord 1994; 7:343-9.

4. Perling LH, Laurent JP, Cheek WR. Epidural hibernoma as a complication of corticosteroid treatment. Case report. J Neurosurg 1988;69:613-16.

5. Robertson SC, Traynelis VC, Follett KA, et al. Idiopathic spinal epidural lipomatosis. Neurosurgery 1997; 41:68-75.

6. Bednar DA, Esses SI, Kucharczyk W. Symptomatic lumbar epidural lipomatosis in a normal male. A unique case report. Spine 1990;15:52-3.

7. van Rooij WJ, Borstlap AC, Canta LR, et al. Lumbar epidural lipomatosis causing neurogenic claudication in two obese patients. Clin Neurol Neurosurg 1994; $96: 181-4$

8. Giuffrè R. Intradural spinal lipomas. Review of the literature (99 cases) and report of an additional case. Acta Neurochir (Wien) 1966;14:69-95. 


\section{BMJ Case Reports}

9. Hinck VC, Clark WM. Normal interpediculate distances (minimum and maximum) in children and adults. Am J Roentgenol 1966;97:141-53.

10. Thomas JE, Miller RH. Lipomatous tumors of the spinal canal. A study of their clinical range. Mayo Clin Proc 1973;48:393-400.

11. Lisai $\mathbf{P}$, Doria $C$, Crissantu L, et al. Cauda equina syndrome secondary to idiopathic spinal epidural lipomatosis. Spine 2001;26:307-9.
12. Schizas C, Ballesteros C, Roy P. Cauda equina compression after trauma: an unusual presentation of spinal epidural lipoma. Spine (Phila Pa 1976) 2003;28:E148-51.

13. Fessler RG, Johnson DL, Brown FD, et al. Epidural lipomatosis in steroidtreated patients. Spine 1992;17:183-8.

14. Guegan Y, Fardoun R, Launois B, et al. Spinal cord compression by extradural fat after prolonged corticosteroid therapy. J Neurosurg 1982;56:267-9.

This pdf has been created automatically from the final edited text and images.

Copyright 2011 BMJ Publishing Group. All rights reserved. For permission to reuse any of this content visit http://group.bmj.com/group/rights-licensing/permissions.

BMJ Case Report Fellows may re-use this article for personal use and teaching without any further permission.

Please cite this article as follows (you will need to access the article online to obtain the date of publication).

Chibbaro S, Mirone G, Nouri M, Di Emidio P, Polivka M, Marsella M, George B. Dorsal epidural spinal lipomatosis. BMJ Case Reports 2011; 10.1136/bcr.09.2010.3365, date of publication

Become a Fellow of BMJ Case Reports today and you can:

- Submit as many cases as you like

- Enjoy fast sympathetic peer review and rapid publication of accepted articles

- Access all the published articles

- Re-use any of the published material for personal use and teaching without further permission

For information on Institutional Fellowships contact consortiasales@bmjgroup.com

Visit casereports.bmj.com for more articles like this and to become a Fellow 